\title{
11. Program Management and Organisational Change: New Directions for Implementation
}

\author{
Lynelle Briggs, Australian Public Service Commissioner
}

\section{The Issues}

Effective and responsive program management is not simply about technique. Rather, we are here concerned with the much harder job of changing our organisations. This leads neatly to the question of why do we need to change? What problems, what issues, what challenges are we responding to?

The answer to these questions will, of course, vary depending on the very specific contexts of our agencies, and the public sector jurisdiction in which we work. There are, however, a number of 'generic' factors common to Australia and other advanced countries that are driving change across Australia's public sector.

I want to look briefly at those that I regard as especially important for organisational change. They are:

- community or citizen expectations,

- challenges to implementation,

- organisational performance,

- complex, difficult and seemingly intractable, or 'wicked', problems, and

- political interest and will to improve the realisation of policy goals.

\section{Community Expectations}

Australians are much more sophisticated consumers of government services than they were only a few decades ago. They are much better educated, much wealthier and benefit not only from a supportive social safety net, but also from the convergence of new administrative law in the 1980s and widespread access to media and information and communication technologies. With this improvement in Australian's standard of living, our focus has switched from the Government providing the basic fundamentals of health care, shelter and welfare towards the overall quality and standard of government services.

Yet, as we have become wealthier and more sophisticated, we are no happier and we demand more from governments than ever before. The Australian community now expects high quality, seamless, accessible and responsive service delivery .... and that's how it should be! 


\section{Implementation Problems}

At the same time, the Australian public sector has become more efficient, effective and innovative at delivering government services. It is, then, somewhat paradoxical that successive governments at all levels in Australia have been bedevilled by implementation problems, or by programs going off the rails.

There is no one particular cause, more a reflection of a multitude of sins - for example, where policy design has failed to properly take account of the challenges to implementation, resulting in cost overruns, unexpected delays and poor outcomes; or where officials have failed to get across to governments the problems of underinvestment in essential aspects of programs; or where we have not appreciated the time that it might take to get key stakeholders on side; or where officials have not kept their eyes on the target or have let the ball drop; or where we have simply failed to appreciate the higher standards demanded of us today.

\section{Organisational Performance}

Everyone knows that the world is changing constantly. Many of us have trouble just keeping up and, yet, the spot light is on all of our organisations' performances and how they might be improved, in the wake of productivity requirements, tighter budgets, higher community expectations and so on. Our goal really should be to move from a leading edge public sector, where we are now, to an outstanding one. That's why organisational change is so closely linked with effective program management.

\section{'Wicked' Problems}

Complicating the picture even further are what Peter Shergold describes as 'wicked problems' - complex and intractable issues, such as the health and economic well-being of Aboriginal and Torres Strait Islanders, balancing environmental protection and economic growth, social under classes and welfare dependency and national security; problems that are seemingly resistant to government intervention. ${ }^{1}$

These are the sorts of problems that urgently need to be both the focus of new thinking (informed by past experience) and subject to leadership that employs dynamic and citizen focussed techniques - that are integrated and coordinated across agencies and jurisdictions. On top of that, there needs to be a commitment to directing the right level of resources to the task.

It is in this context that we have seen, in Australia and around the world, a focus on connecting government; on whole of government solutions to hard problems; on working across agencies and across jurisdictions; and on horizontal governance that involves stakeholders in the design, planning and implementation of government programs. 
We are, of course, also seeing new and innovative approaches in many areas, but the point is that there is more to do, and there are no one-size-fits-all solutions. Many of these 'wicked' problems-addiction, obesity, welfare dependence - require behavioural change. Much of the recent policy design in these areas is underpinned by notions of shared responsibility and self reliance, and an acknowledgement that governments cannot achieve their objectives without the support and involvement of the community, or without increased cooperation and collaboration between sectors and agencies-more 'co-productions' (as ANZSOG is known to describe them).

This approach is evident, for example, in remote Aboriginal and Torres Strait Islander communities where communities make commitments (to improve school attendance, reduce drug and alcohol use, for example) and governments undertake to provide services or funding to assist the community to achieve their objectives (through Regional Partnership Agreements and Shared Responsibility Agreements).

\section{Political Will and Interest}

Responsiveness to the elected government was a key theme of the watershed report of the Coombs Commission into Australian Government administration in the mid-70s, and was generally understood in terms of how the Government's intentions were translated into policy.

What we are seeing today is a determination by the Government to have greater influence on the timely and effective delivery of their policy interventions. Governments want to see some 'bang for their bucks' - clear improvements as a result of their interventions. They do not want to see their money fritted away or unspent through poor planning or bureaucratic time wasting or incompetence. Indeed, Peter Shergold said last week that '[e]very government knows that its future depends not only on how wisely it makes decisions but on how effectively its public service delivers them'.

It is, therefore, not surprising that the Australian Government has moved to push for a greater focus on Government outcomes and to make some important structural changes at the delivery end.

It has established the Cabinet Implementation Unit, within the Department of the Prime Minister and Cabinet, to encourage earlier and more effective planning for implementation of public policy decisions delivered through government programs and services.

It is implementing the findings of the Uhrig Review of Corporate Governance of Statutory Authorities and Office Holders to clarify lines of accountability between agencies and Ministers and relationships between agencies and their portfolio departments. 
What we are seeing here is a determination to get the right governance arrangements in place, as a foundation for improved delivery and implementation of the Government's policy initiatives. This is not a shift away from devolution, but an enhancement, with a focus on achieving better results for the Australian community within a devolved environment.

To this end, in 2004 the Government created the Department of Human Services, which brings together six agencies, as a means to improve co-ordination between them, improve their responsiveness to Government direction, and to raise the quality of the services they deliver. The Prime Minister said at that time:

[O]ne of the things we lack in the public service both at a Commonwealth and a State level is a consolidated focus on the efficient and timely and sympathetic delivery of services. We tend to look at service delivery as an afterthought rather than as a policy priority.

Of course, the political interest in the nuts and bolts of public administration is not limited to Australia. In the UK recently the House of Commons Public Administration Select Committee launched an inquiry into the place of strategy and planning in government. It will explore, among other things, whether strategic planning is too centralised, or not centralised enough; how people are best trained to carry out strategic planning; and whether Parliament should have a greater role in the strategic planning process.

It raises in my mind that classic question of when is it appropriate to bring project management skills into the policy process? I guess, the answer must surely be, as soon as possible - the two are, after all, part of a wider program management continuum.

\section{The Focus of this Conference}

These, then, are some of the complex problems, issues and developments that have inspired this conference. The focus of the conference is project management and organisational change. Its fundamental message is that implementation must be taken seriously, and that we can, and we must, do it better.

In the time that remains I would like to outline my views about what I think of as an evolved concept of program management.

\section{A More Evolved Sense of Program Management}

In the early 80s, when I was working in the then Department of Social Security, 'program management' was used in a limited sense of 'to run' a program. With the advent of the 'new public management' it evolved to reflect new styles of operating in the public sector. The use of the term very likely records the shifts and nuanced adjustments that have occurred in public administration in the last two to three decades. 
Today, the sense in which I am using 'program' describes the overall intervention by the Government which is intended to bring about change that is consistent with a policy position. Welfare to Work, the Regional Partnerships program, or Australia's skilled migration program are classic examples.

In this contemporary sense, program management is the discipline of delivering, directly or indirectly, the outcomes and outputs that contribute to achieving a policy objective of the Government - for example, to support elderly people with low income in their retirements; or to assist business and community development in regional areas; or to provide more effective government services to Aboriginal and Torres Strait Islander communities.

The type of integrated and coherent program management framework that I see evolving in the Australian Public Service operates on two levels: the systemic or public service-wide level, and at the agency level.

At the agency level, officials manage particular programs and work with others to facilitate the delivery of Government policy objectives.

At the systemic level we are seeing a whole of government approach to the monitoring of implementation of Government policy decisions. This is happening through the Cabinet Implementation Unit is 'traffic light' report, and the 'gateway' review system being developed by the Department of Finance; a focus across the APS on learning from experience; capability building through development programs, and, importantly, by ensuring greater exposure of people to service delivery and implementation issues.

The discipline imposed by program management not only helps to articulate the relationship between aspects of the program's outputs, but seeks also to ensure that they are integrated so that 'the whole is worth more than the sum of its parts'.

A commitment to program management recognises that responsibility for developing and implementing the Government's major programs often crosses organisational and jurisdictional boundaries, and requires joint agreement about what is to be achieved and how that will happen.

As it has evolved, program management has taken on a 'change' focus. The term itself implies, in my view, a responsiveness to the environment (political, social, cultural, strategic) that drives change; but also changes to structures and processes, to a more strategic focus on expected outcomes and, if necessary, to culture - with a clear view to achieving the Government's policy objective. ${ }^{2}$

For program management to be effective in this new environment, organisations must change to move with it and to deliver on the Government's objectives. 


\section{Active Program Management}

What I think this conference reflects is a determination to follow through on a cultural shift that has been taking place in the public sector-where we are finally shaken loose from our silos, where we move past the rhetoric of whole of government working, to what I think of as an active or dynamic form of program management.

What do I mean by active program management? I mean that it is not sufficient to simply have the elements of good corporate governance in place - to have ticked the boxes-corporate plan-tick; strategic plan-tick; service charter - tick. Rather, what is required is a framework that actively supports program managers (and project managers below that) to manage their piece of the puzzle and to understand and manage the intersections with other areas of their business. ${ }^{3}$ Some of the important elements of such a framework include: ${ }^{4}$

- $\quad$ sophisticated scoping, planning and timing (including business case, setting of milestones etc);

- $\quad$ putting in place appropriate milestones, success criteria, and measures for quality assurance;

- proper and early assessment of risks and strategies for their handling;

- stakeholder management and communications strategy;

- ensuring all the resources are in place (human as well as financial);

- ongoing monitoring to ensure that the program continues to meet its objectives;

- we should also build into the management of our programs:

- consideration of whether the program is having its intended effect and, if not, take corrective action (for example, suggest policy changes or changes to guidelines);

- processes for advising the Minister of progress, developments and outcomes;

- measures to achieve efficiencies or improvements in administration of our programs;

- audit and evaluation processes, including sound management information systems, to assess how program and project outcomes are shaping up in relation to the objectives of the program;

- given the trend to increasingly work through others for the delivery of Government services, we also need to employ partnership approaches, effective contract design and management and procurement processes; and

- we need to come to grips with the new governance and accountability issues these approaches bring - to find effective ways of marrying vertical and horizontal lines of accountability, and to understand that ultimately (whether we like it or not) accountability for program performance and outcomes still remains with us. 
Active program management promotes efficient and effective use of Commonwealth resources, particularly by ensuring that expensive rectification measures - for programs gone wrong - are not required.

We've been on a fairly steep learning curve in the APS as the financial management and related skills (including contract management and procurement) expected of us have expanded. I think there's been a tendency for over-confidence, followed by some predictable fall-out. Financial management is a core competency and has to be managed year in and year out to ensure not only that existing projects are supported, but that new projects - responding to new challenges and new policy directions - can be implemented well.

Program failures, through botched program management, result in damage to the reputation of the APS, and undermine the level of trust in government amongst those that are the focus of the program and amongst the community more generally. The snowball effect of unhappy customers equally applies to the public sector as in the private sector — word spreads quickly; therefore active and effective program management is essential.

Programs, in whatever form, are never static. They need to be actively managed with a critical eye for their nuancing and further development or even their replacement by something better-bringing us back to organisational change and project management.

\section{Program Management Capabilities}

Peter Shergold describes implementation as the 'heavy lifting' — as opposed to policy advising which he says is often seen as the 'zenith of apolitical courage'. Implementation, he argues, is the point at which 'courage' is most needed, undertaken as it is in the public gaze and subject to intense scrutiny. ${ }^{6}$ It is the point at which the policy is judged to have succeeded or failed.

It would, therefore, be remiss of me not to refer explicitly to the capabilities that we need in the public sector to achieve the integrated program management and high standard of outcomes we aspire to, and which the Government and the community demands.

Program management requires a diverse set of capabilities, including, but not limited to:

- financial management;

- risk management;

- contract management;

- change management;

- relationship management;

- strategic management;

- project management; and 
- influencing skills.

Even a cursory glance at the Senior Executive Leadership Capability (SELC) Framework - the criteria against which senior executives in the Australian Public Service are selected and developed - gives a sense of the wide ranging skill sets required to perform the business of government.

Dynamic and integrated program management does not require a new super-breed of public servant - but we are clearly looking to recruit people with a different and more diverse mix of skills than we have in the past. It is not surprising, then, that the APS has become a 'graduate' workforce. Overall, about half of us have graduate qualifications, and 64 per cent of new recruits (who mostly do not enter through graduate programs) are graduates. ${ }^{7}$

Changing capability requirements are also reflected in the learning and development programs that the Australian Public Service Commission offers. I am committed to the development of programs by the Commission that are responsive to what agencies need, and to supporting agencies align their business objectives with their organisational cultures.

A common thread is the importance of a strong, strategically orientated APS leadership team. The Commission plays a central role in the development of APS leaders and over the next few months I will be unveiling a new suite of leadership programs for the SES. We have already begun reinvigorating our EL programs to focus more on regulatory activity, service delivery, policy development and program management. I am hoping to launch our new program management training programs by the middle of the year.

Attracting people with the right mix of capabilities is critical to the success of program management in the APS - we need the right people in the right jobs at the right time. A feature of the project management approach you will hear about today and tomorrow is the explicit focus on looking at what you're trying to achieve and actively matching the skills that are required to bring it about. I am very firmly of the view that we need to be much better at this in the public service.

The latest Management Advisory Committee report on managing and sustaining the APS workforce highlights some of the significant challenges we are going to confront in the coming decades, as we respond to population ageing and workforce constraint and as we compete to maintain our specialist and technical skills.

Added to this, though, is the need for public servants to reflect personally on what they can do to align their behaviours and attitudes with the changes evident in modern government program directions, and what they might do to work towards moving the cultures of entire public sector organisations towards greater 
alignment. It is this sort of thoughtfulness and action that is necessary, amongst other things, if we are to reach the gaol of an outstanding public service.

\section{Program Management 'take-aways'}

To sum up, the messages that I would like to leave you with about the evolving concept of program management are that:

- program management seeks to provide coherence in the context of (ever increasing) complexity;

- program management is a dynamic and integrated process that drives change in order to achieve the Government's policy objectives;

- program management provides clarity about the roles of people and agencies, so that responsibilities and accountabilities are also clear;

- program management often requires responsibility and accountability across boundaries;

- $\quad$ program management helps to identify and resolve tensions between different aspects of a program - including through the alignment of business objectives with organisational culture; and

- program management requires a diverse set of capabilities and active engagement to use them and to change cultures and practices;

Ultimately, good program management will impact positively on trust in government, citizen engagement and good outcomes for the Australian community.

\section{Conclusion}

We are all heading in much the same direction-looking to achieve better alignment of our organisational cultures and business objectives so as to achieve better outcomes for the communities we serve. The language we use to describe what we're doing will, undoubtedly, vary between agencies to some extent, and more so across jurisdictions and sectors. The fundamental message remains, however, that we must do implementation better and that we can do it better.

\section{References}

Bridgman, P. and Davis, G. 2000, The Australian Policy Handbook, 2nd edition, Allen and Unwin, St Leonards, NSW.

Marsh, I. 1999 'Program strategy and coalition building as facets of new public management', Australian Journal of Public Administration, Blackwell Publishers, December, 58 (4).

National Audit Office, 2001, Modern policy-making: ensuring policies deliver value for money. Report by the Comptroller and Auditor-General, HC 289 Session 2001-2002: 1 November. 
Normington, D. David Normington's 5 non-negotiable elements of program management, Department for Education and Skills, United Kingdom, http://www.dfes.gov.uk/ppm/index.cfm?fuseaction = content.view $\&$ CategoryID $=30 \&$ ContentID $=199 \&$ SiteID $=1$.

Shergold, P, Regeneration: New Structures, New Leaders, New Traditions, speech delivered at the Institute of Public Administration Australia National Conference, Canberra 11 November 2004. http://www.pmc.gov.au/speeches/ shergold/regeneration_2004-11-11.cfm

Australian Public Service Commission, 2005. State of the Service Report 2004-05, Commonwealth of Australia, Canberra, http://www.apsc.gov.au/ stateoftheservice/ index.html

\section{ENDNOTES}

${ }^{1}$ Bridgman and Davis (2000: 43-44) describe wicked problems as 'issues that cannot be settled and will not go away'; they typically involve '[h]istorical factors, competing interests or sunk costs ... mak[ing] all sides to a dispute unwilling to compromise'.

2 Marsh (1999:54) has identified a range of elements required for strategic thinking in program management: continual monitoring of outcome effectiveness, identifying alternative ways in which to configure a program, and monitoring emerging issues and trends and the identifying the implications of those for the existing program.

${ }^{3}$ Marsh (1999:54) characterises program managers as 'legitimate change agents', and suggests that active engagement is critical to their role.

4 Normington refers to ' 5 non-negotiables for program management': clarity on objectives, leadership and roles, boundary working, risks, timelines and milestones.

5 The UK Auditor-General's 2001 report, Modern policy-making: ensuring policies deliver value for money, suggests some essential considerations for active management of policy delivery:

1. A program is not always relevant or effective in a static form, and as a result there must be continual monitoring of effectiveness

2. The needs of the group(s) targeted by a program may change or evolve

3. As time progresses, there may be opportunities for savings and efficiencies to be realised in the delivery of the program

4. Program managers working in a whole of government context must be aware of, and, where appropriate respond to, changes that partner agencies make to their parts of the program delivery.

6 Shergold, P, Regeneration: New Structures, New Leaders, New Traditions, speech delivered at the Institute of Public Administration Australia National Conference, Canberra 11 November 2004.

7 State of the Service Report 2004-05, p.150 